
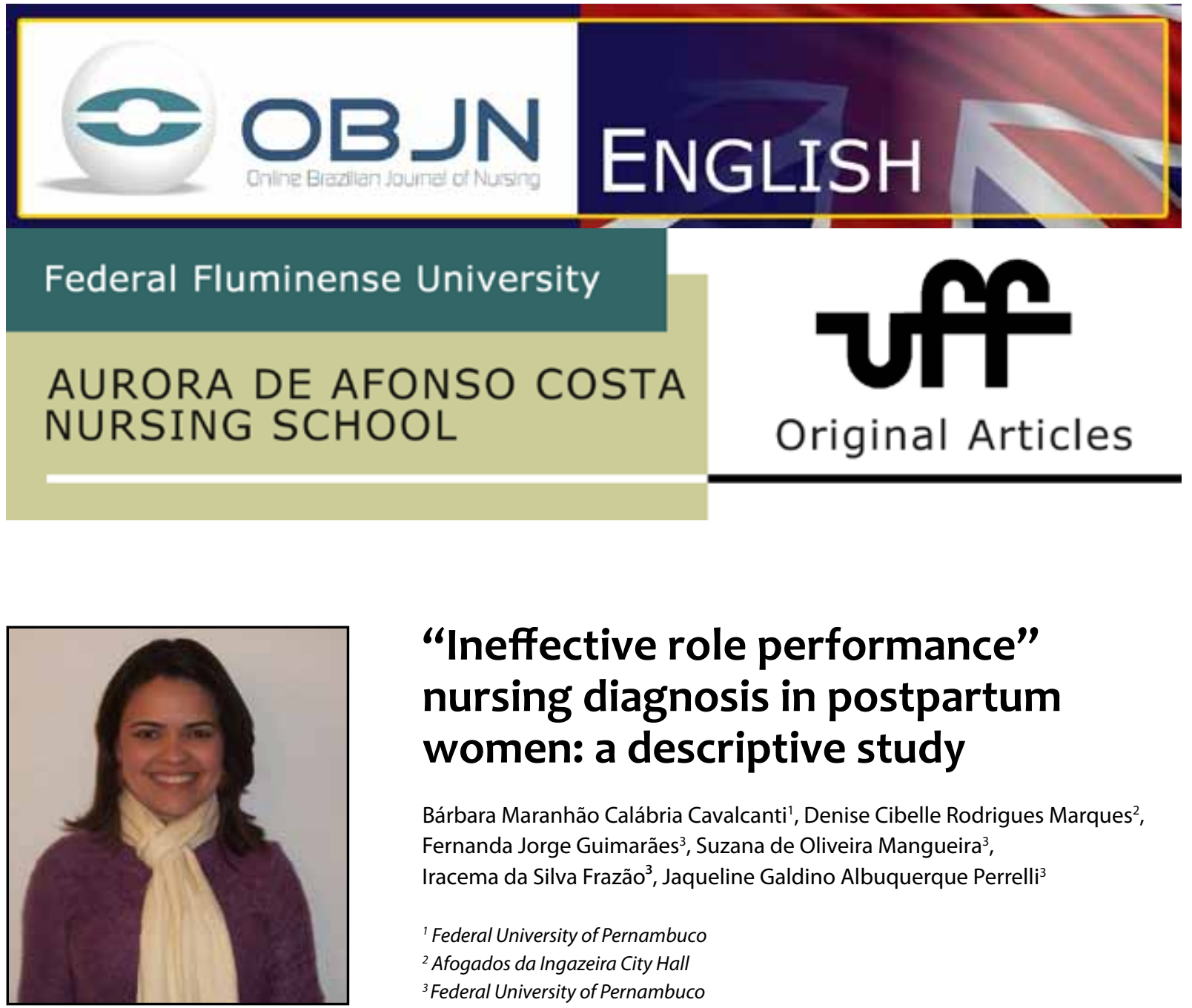

\title{
"Ineffective role performance" nursing diagnosis in postpartum women: a descriptive study
}

\author{
Bárbara Maranhão Calábria Cavalcanti', Denise Cibelle Rodrigues Marques², \\ Fernanda Jorge Guimarães ${ }^{3}$, Suzana de Oliveira Mangueira ${ }^{3}$, \\ Iracema da Silva Frazão ${ }^{3}$, Jaqueline Galdino Albuquerque Perrelli \\ ${ }^{1}$ Federal University of Pernambuco \\ ${ }^{2}$ Afogados da Ingazeira City Hall \\ ${ }^{3}$ Federal University of Pernambuco
}

\begin{abstract}
Aim: To investigate the "ineffective role performance" nursing diagnosis in postpartum women at family health centers. Method: A descriptive study was carried out in cities in interior Pernambuco, with a sample of 51 postpartum women. The component elements of the diagnostic presented were identified through the Postpartum Depression Screening Scale - PDSS. Results: We identified ineffective role performance in $52.9 \%$ of the sample. Anxiety, inadequate self-adaptation, and inappropriate self-control, were the most frequent defining characteristics. Disadvantaged economic status, stress and low levels of education were factors associated with the high percentage. Discussion: the phenomenon is correlated with depressive symptoms in the postpartum period as indicated in PDSS, especially anxiety and irritability, that substantially interfere in the relationship between mother and child. Conclusion: PDSS allowed the determination of a human response in the postpartum period, so it is an important instrument to be introduced in the professional activities associated with the Family Health Strategy program.
\end{abstract}

Descriptors: Nursing Diagnosis; Mother-Child Relations; Role Playing; Depression, Postpartum. 


\section{INTRODUCTION}

Motherhood is a process in the life of women that begins before pregnancy. This is a time of planning, anticipation and desire to be a mother. During pregnancy, the mother interacts with her baby inside her belly, with routine talking, observing fetal movements, besides assigning physical, social and emotional characteristics to her child. That's how the first attachment relationships between the mother and her baby are formed ${ }^{(1)}$.

Bowlby's Attachment Theory ${ }^{(2)}$ suggests that there is a human need to develop close emotional bonds in terms of the biological function of the survival of the species, from the fetal stage to old age. In childhood, these emotional interactions are primarily developed within parents, in order to bring comfort, protection, affection and love. In adolescence and adulthood, these relationships are enhanced and modified, and new bonds with other important people are developed and aggregated.

After birth, the narrowing of that emotional bond between parent and baby happens in an individualized and specific manner, depending on the response of everyone involved in the process. The puerperium is the time when the whole process of pregnancy and childbirth is consolidated leading to the beginning of a new phase in life, as parents have the opportunity to meet their child, touch him or her, provide care and exercise their role. The baby responds to these moments of interaction, and communicates as to whether they are pleasant or not ${ }^{(1.3)}$.

Bowlby's theory considers that the quality of these relationships, specifically between mother and baby, has a direct influence on the mental health of the child, and should therefore be warm, intimate, loving and continuous, providing pleasure and comfort for both ${ }^{(2)}$.
However, it is known that pregnancy and childbirth makes women more vulnerable to psychologicalchanges, including mental disorders during the puerperium, especially postpartum depression (DPP) ${ }^{(4)}$. A review showed that, in Brazil, the rates of occurrence of this disorder range from $7.2 \%$ to $43 \%{ }^{(5)}$.

This disease is defined as a mood disorder that is evident in the first weeks after birth, and has negative consequences for the mother, baby and family. The symptoms are depression, fatigue, sleep disturbance, lack of concentration, crying crisis, lack of interest in daily activities, and loss of pleasure. Suicidal thoughts and feelings of excessive guilt ${ }^{(4)}$ may be present.

These symptoms substantially interfere in the care of the mother for the newborn, which negatively affects their role as mothers. Thus, there is a need to investigate which factors predict the appearance of this condition in women in the postpartum period, so that the nurses can intervene and minimize the damage in the relationship between mother and child, as well as caring for the mental health of both.

The nurse is associated with a series of activities in women's health, especially during pregnancy and childbirth, from the prenatal to the postpartum period ${ }^{(6)}$. In addition, during the first years of a baby's life, the nurse follows the growth and development of the child, and has the opportunity to observe the difficulties experienced by women in the exercise of their role as mothers.

However, in their planning, the nursing care programs do not include aspects of care regarding the mental health of that population. This fact may be related to a deficiency in terms of training in this area, and the absence of specific mental health programs that enable nurses to identify the risk situations that will guide their interventions. 
Therefore, in order to provide accurate information that can structure the work processes of the nurse with regard to the mental health of women in the postpartum period, this study focuses on the identification of the "ineffective role performance" nursing diagnostic.

This phenomenon is presented by the NANDA International Taxonomy and is defined as"... patterns of behavior and self-expression that do not match the context, norms and expectations of the environment" ${ }^{\prime \prime(7)}$.

In this study we seek knowledge about the psychosocial needs of women in the postpartum period, which will guide the nursing interventions in such a way as to promote the mental health of the woman, and help her with the role of being a mother.

Given the above, the aim of this research was to identify the nursing diagnostic of the "performance ineffective role" in postpartum women, based on a screening scale for postpartum depression.

\section{METHOD}

\section{Nature of the study}

This is a descriptive study which adopts a quantitative approach, developed in three Family Health Centers (USF) located in cities in the Pernambuco area. It should be noted that in these units the nurses do not develop any specific activities directed at promoting the mental health of women. This fact marks the importance of the application of this study in healthcare settings.

\section{Population and sample}

The population consisted of mothers who attended three USF. Inclusion criteria were: women from 15 to 49 years of age who were between two to twenty six weeks postpartum, and who are literate. The death of the newborn during the data collection period and moving away from the USF coverage area were the exclusion criteria. The sample consisted of 51 women, consecutively selected as they fitted the pre-established inclusion criteria. Participants who agreed to participate signed an informed consent form (ICF).

\section{Study Variables}

The following defining characteristics of the diagnostic in question were investigated: inadequate adaptation to change, anxiety, inadequate self-control, depression, ineffective role performance, inadequate coping, uncertainty, dissatisfaction with the role, altered perception of role, pessimism and helplessness. In addition, the factors that were investigated were lack of education, chronic and situational low self-esteem, depression, disadvantaged economic status, stress and young age.

The defining characteristics and related factors cited related to the Postpartum Depression Screening Scale (PDSS) developed by Beck and Gabler $^{(8)}$. This instrument has been adapted and validated for the Brazilian women population and has a high reliability coefficient $(a=0.95)^{(9)}$. Therefore, in order to provide precise and accurate findings, we chose to use this scale to identify the elements of the "ineffective role performance" nursing diagnostic. Each item of the scale was analyzed in order to determine the presence or absence of characteristics and factors related to the phenomenon under consideration.

\section{Data collection procedure and instrument}

The PDSS is a self-administered scale with Likert-type responses that assess the intensity 
level of symptoms. The instrument contains 35 items divided into seven dimensions: disturbances in sleep/appetite, anxiety/safety, emotional lability, cognitive impairment, loss of self, guilt/ shame and the intent to cause harm to themselves. Each dimension consists of five items describing the feelings of the mother after the birth of her baby ${ }^{(8,9)}$.

Data were collected from February to March 2011 during the postpartum home visit and/or childcare consultation at USF. The women were asked to indicate their degree of agreement or disagreement with each PDSS item at a level from strongly disagree (1) to strongly agree (5). To complete the instrument, the woman was asked to tick the answer that best reflected her mood in the two weeks prior to the collection. The cutoff for indicating symptoms of PPD is $102^{(9)}$.

\section{Data analysis}

The scale items were entered into an Excel version 2003 spreadsheet, and were associated with the elements of nursing diagnosis ${ }^{(7)}$ in terms of defining characteristics and related factors as shown in a previous topic.

After this stage, two nurses rated the items and their association with the defining characteristics and related factors, and checked these last two elements to determine the presence or absence of "ineffective role performance". When there was disagreement between the pair, a third nurse was asked to assess the phenomenon.

Data were analyzed with the support of the Statistical Package for Social Sciences (SPSS) version 17.0. Absolute and relative frequencies were used to describe the variables. The association between the nursing diagnostic and related factors was done using chi-square or Fisher's exact test pattern.

The study was submitted to the Ethics Committee of the Health Sciences Center of the
Federal University of Pernambuco (CEP / CCS / UFPe), and the researchers obtained permission by official letter, number 324/2011. Aspects contained in Resolution 466/12 on human research of the National Board of Health/Ministry of Health ${ }^{(10)}$ have been met.

\section{RESULTS}

Participants were aged between 16 and 36 years, with an average age of 25.06 years. Approximately $70 \%$ of the assessed women live in urban areas. The average number of children per family was 2.39 . Regarding their marital status, $47.1 \%$ were married and $43.1 \%$ were in a stable relationship. With regard to schooling, $41.2 \%$ had completed high school. Regarding their occupation, more than half (51\%) were housewives. Concerning the planning of pregnancy, about $10 \%$ of the mothers had not planned to become pregnant and were in the age group 16-27 years.

As already mentioned, we used the screening scale (PDSS) to identify the defining characteristics and related factors with regard to "ineffective role performance". The data are presented in Table 1.

Table 1: Distribution of the defining characteristics and related factors of nursing diagnosis of ineffective role performance in postpartum women. Vitoria de Santo Antão - Pernambuco 2013

\begin{tabular}{lcc}
\hline \multicolumn{1}{c}{ VARIABLES } & N & $\%$ \\
\hline Defining Characteristics & & \\
\hline Anxiety & 33 & 64.7 \\
Inadequate adaptation to change & 22 & 43.1 \\
Inappropriate self-control & 22 & 43.1 \\
Altered perception about role & 19 & 37.3 \\
Inappropriate coping & 16 & 31.4 \\
Feelings of helplessness & 12 & 23.5 \\
Dissatisfaction with the role & 6 & 11.8 \\
Pessimism & 5 & 9.8 \\
Depression & 4 & 7.8 \\
\hline
\end{tabular}




\begin{tabular}{lll}
\hline Related Factors & & \\
\hline Stress & 28 & 54.9 \\
Low level of instruction (lack of educa- & 25 & 49.0 \\
tion) & & \\
Economic disadvantage & 16 & 31.4 \\
Low self esteem & 9 & 17.6 \\
Youth & 8 & 15.7 \\
Depression & 4 & 7.8 \\
\hline
\end{tabular}

Nursing Diagnostic: Ineffective Role Performance

\begin{tabular}{lll}
\hline Present & 27 & 52.9 \\
\hline Total & 51 & 100.0 \\
\hline
\end{tabular}

Source: Research data

The nursing diagnostic was identified in $52.9 \%$ of the postpartum women interviewed. As for the defining characteristics, the most common were anxiety (64.7\%), inadequate adaptation to change (43.1\%) and inadequate self-control (43.1\%). Finding themselves in a disadvantaged economic situation, under stress and with low levels of education were the most common related factors. In contrast, although low self-esteem (15.7\%), youth (15.7\%) and depression (7.8\%) scored less, these are highly relevant indicators for the identification of changes in the motherhood exercise. Table 2 shows the association between the related factors and the presence of the nursing diagnostic in question.

Table 2: Association between the factors related and the presence of the nursing diagnostic of ineffective role performance in postpartum women. Vitoria de Santo Antao - Pernambuco 2013

\begin{tabular}{lccc}
\hline \multicolumn{1}{c}{ VARIABLES } & $\mathbf{N}$ & $\%$ & Valor $\mathbf{p}$ \\
\hline Related factors & & & \\
\hline $\begin{array}{l}\text { Stress } \\
\text { Low level of instruction (lack }\end{array}$ & 25 & 54.9 & $<0.001^{*}$ \\
of education) & 16 & 31.4 & $0.749^{*}$ \\
Economic disadvantage & 9 & 17.6 & $0.002^{*}$ \\
Low self esteem & 8 & 15.7 & $0.120^{*}$ \\
Youth & 4 & 7.8 & $0.13^{* *}$ \\
\hline Depression & & &
\end{tabular}

Source: Research data

${ }^{*}$ Chi-square test; ${ }^{* *}$ Fisher's exact test

\section{DISCUSSION}

The "ineffective role performance" diagnostic is present in the daily lives of women at USF, and so it is a phenomenon that requires nursing intervention in order to assist women in their role as mothers.

The findings showed that approximately $50 \%$ of the participants work in activities that require them to be absent from home, which makes it harder for them to devote more time to caring for the baby. A study on the experience of motherhood has shown that mothers who choose to move away from their children due to work, have high levels of guilt and inadequacy when it comes to being a mother. This fact was associated with a greater anxiety at being separated from the baby, and the feeling of being the only person able to take care of the newborn, resulting in resistance and even rejection of alternative care ${ }^{(11)}$.

Regarding the level of education, nearly half reported less than ten years of study. The low levels of education increases the chances of an unwanted or unplanned pregnancy, affecting mainly the younger age group, and is responsible for the disruption of expectations and aspirations in terms of future plans ${ }^{(12)}$.

However, when the pregnancy is planned and desired, some of the teenagers have positive expectations about their future and their baby. Also, after the baby is born, their dreams and goals come true and allow them to provide what is best for their child ${ }^{(12)}$. The data corroborate the findings in the sample, because the majority $(90.4 \%)$ of the women studied said that they planned or desired the pregnancy.

Anxiety has been the focus of some researchers because of the belief that anxious states are exacerbated in women during the postpartum period ${ }^{(5)}$. During this period, due to the negative effects of anxiety, we can clearly 
see the reduction in the ability to cope with the situations, the decreased sensitivity and increased feelings of ineffectiveness in terms of child care. It also has negative effect on galactopoiesis and on the quality of the mother-infant bond ${ }^{(13)}$.

In this study, the presence of anxiety was clearly evidenced by $64.7 \%$ of the postpartum women, highlighting the importance of an early diagnosis in primary care, since this is the context in which the women have their first contact with the health team.

Therapeutic measures are important because maternal anxiety is not limited to the postpartum period, and can promote long-term effects on affective relationships. Many mothers with high levels of anxiety during the postpartum period have a greater chance of presenting signs of improper adaptation in caring for their children compared to mothers with lower levels of anxiety during this same period ${ }^{(13)}$.

The "inadequate adaptation to change" defining characteristic is seen in the symptoms of PPD as persistent dismay, sleep disturbance, suicidal thoughts, loss of appetite and libido, decreased levels of mental functioning, and the presence of obsessive ideas ${ }^{(14)}$. Baby's night time waking and restless sleep are associated with maternal depressive symptoms. During the night time, the mother performs baby care activities, such as breastfeeding, diapering, among other needs. These activities performed at night are associated with the PPD in terms of impairing the quality of sleep and exacerbating depressive symptoms in such women ${ }^{(15)}$.

The results show that changes in the circadian cycle of the women may result in inadequate adaptation to the changes experienced in this stage of their life. This fact was evidenced in this study, since $43.1 \%$ of mothers presented the "inadequate adaptation to change" defining characteristic.
The feeling of helplessness present in $23.5 \%$ of women became evident in that the mother, after the birth of a child, experiences feelings that may be conflicting and irreconcilable with the idealized image of motherhood dictated by their culture. Thus, it establishes a conflict between the ideal and the experience lived, creating a degree of psychological distress that may occur within postpartum depression ${ }^{(16)}$.

This situation was observed during the period of data collection, since some women were afraid to express their feelings about motherhood in front of a family member, friends, and even to the health team in their community. This is possibly due to the lack of support from the family, especially from the child's father, a fact that contributes to the burden of mothers faced with tasks involving the baby, the house and other children.

The altered perception of role (37.3\%) may be related to the perception of mothers about motherhood, because, prior to being a mother, she was a student, a wife, a housewife, had a steady job, among other duties, and now, she was also a mother with a series of doubts about the process of motherhood in which there are other subjects involved.

An integrative review study examined the change in perception of the role of women when faced with the hospitalization of newborns and found that they reported not feeling completely mothers in that they were not responsible for the care of their child, as they cannot take care of the child in their own way and do not have the relationship they imagined with the baby. This study also showed some testimonials of postpartum women expressing the difficulty of playing the role due to a lack of knowledge about caring for their own baby, due to feelings of powerlessness, or due to not feeling as she ought to as a mother. Some factors contribute to this analysis, such as the 
hypogalactia, which reinforces the perception that their maternal role is not being exercised, and may cause a certain distance to emerge in the mother-infant bond ${ }^{(17)}$.

The postpartum period may be marked by various conflicting feelings such as euphoria and relief, excitement at the birth, feelings of disappointment about the child either because of the baby's gender or its physical appearance, increased self-confidence, and fear of not being capable of breastfeeding. These sentiments reflect the insecurity of not being able to care for and meet the needs of the baby, or fear of not being a good mother ${ }^{(16)}$.

Low self-esteem was a related factor to the "ineffective role performance" diagnostic in $17.6 \%$ of the mothers. Self-esteem is defined as an individual's judgment about himself since his early childhood, and has fundamental importance in his relationship with himself and with others, influencing his perception of events and his own behavior ${ }^{(18)}$.

We observed that, in the locus of the basic health centers used in this study, the prenatal and postpartum activities did not include aspects related to the mother's self-esteem, only referring to the physiological issues related to pregnancy, childbirth, and the postpartum care of the newborn.

Therefore, it is necessarily a reflection on the educational strategy that has been used, so that the mental health of women during this period can be seen as something essential for the creation of a bond between mother and child, in its entirety, without prejudice for anyone involved.

The lack of action for the promotion of women's mental health, along with poor education, unplanned pregnancies and lack of help from the partner after the baby's birth, contributes to the generation of low self-esteem, and may trigger other negative feelings during this period which can influence the affective relationship between mother and child ${ }^{(18)}$.

As for the youth-related factor, it is worth noting that pregnancy in this period of life, in most cases is faced with difficulty, because it reflects a transition phase, in which the woman rapidly passes from the condition of being a daughter to that of being a mother. In this abrupt transition, the young mother experiences social and familial losses that directly impact on her emotional state. This fact may have psychological consequences, and the appearance of signs and symptoms which could jeopardize a healthy pregnancy ${ }^{(18)}$.

PDSS screening revealed that $7.8 \%$ of the sample had scores indicating postpartum depression. This disorder is identified in the nursing diagnosis process as a defining characteristic, and also as a factor related to the "ineffective role performance" diagnostic.

Depressive symptoms do not always reveal a condition. However, in pregnancy and during the postpartum period, they may be associated with other factors such as anxiety and irritability, and may progress to a pathological process that is difficult to diagnose.

Anxiety is related to the decreased responsiveness and attention being paid to the needs of children by depressed mothers. This is a warning sign that draws attention to an impending danger, and enables the individual to take action to deal with the threat, while the irritability of a mother refers to the greater expression of negative affection and lower tolerance with child behaviors $^{(17)}$.

In this study, we identified four women with signs of PPD. This is quite significant, since it is equivalent to approximately $8 \%$ of the sample.

In addition, 27 of the participants had difficulties when it came to playing the role of mother, for several reasons. Among them were some depressive symptoms in the postpartum 
period and even other features that did not translate into a disorder, but were in a situation in which nurses can intervene with competence.

\section{CONCLUSION}

The use of the PDSS self-assessment scale allowed the determination of a human response in the postpartum period and the tracking of postpartum depression in the primary care context. It is an important instrument that ought to be introduced into the activities of the professionals involved in the Family Health Strategy program.

The nurse has the authority to use such an instrument in order to qualify the care offered to women in the postpartum period, or even during pregnancy. Specifically regarding the "ineffective role performance" diagnosis, it was observed that the anxiety and the adaptation to the role of mother, as well as the perception of women with regard to maternity, were aspects present in the studied sample and ones that deserve special attention on the part of the nurse assisting them.

The study has limitations related to sample size and the quantitative USFs used as the place of research. Therefore, it is suggested that there is a need to carry out further studies with a larger sample from different health units that treat issues related to women's mental health, especially those related to their mood during pregnancy and postpartum that influence their role as mothers.

\section{REFERENCES}

1. Brazelton TB. Momentos decisivos do desenvolvimento infantil. 2. ed. São Paulo: Martins Fontes; 2002.
2. Bowlby J. Apego: A natureza do vínculo. 3. ed. São Paulo: Martins Fontes; 2002.

3. Salim NR, Santos Junior HPO, Gualda DMR. Everyday behavioral and physical changes in women during the postpartum period - a qualitative approach Online braz j nurs [serial in the Internet]. 2010 [citado em 2014 mar 22]; 9(1). Available from: http://www.objnursing.uff.br/index.php/ nursing/article/view/j.1676-4285.2010.2785

4. Patel, MD et al. Postpartum depression: a review. Journal of Health Care for the Poor and Underserved. 2012 [cited 2014 mar 22]; 23(2): 534-542.

5. Cantilino A, Zambaldi CF, Sougey EB, Júnior JR.Transtornos psiquiátricos no pós-parto. Rev Psiquiatr Clín. 2010 out [citado em 2014 mar 22]; 37(6): 288-294. Disponível em: http://www.scielo. br/pdf/rpc/v37n6/a06v37n6.pdf

6. Ministério da Saúde (Brasil). Secretaria de Atenção à Saúde. Atenção ao Pré-Natal de baixo risco: manual técnico. Brasília: Ministério da Saúde; 2012.

7. Herdman, TH. Diagnóstico de Enfermagem da NANDA: definições e classificações. 2012-2014. Porto Alegre: Artmed; 2012.

8. Beck CT, Gable RK. Postpartum depression screening scale: development and psychometric testing. Rev.Nurs Res. 2000 [cited 2014 mar 22]; 49 (5): 272-282.

9. Cantilino A, Carvalho JA, Maia A, Albuquerque C, Cantilino G, Sougey EB. Translation, validation and cultural aspects of postpartum depression screening scale in Brazilian Portuguese. Transcult Psychiatry. 2007 [cited 2014 mar 22]; 44(4):67284.

10. Conselho Nacional de Saúde (Brasil). Resolução 46612 Aprova diretrizes e normas regulamentadoras para pesquisas envolvendo seres humanos (revoga as seguintes resoluções: 196/96, 404/08 e 303/00). Available from: http://conselho.saude. gov.br/resolucoes/2012/Reso466.pdf

11. Souza DD, Prado LC, Piccinini CA. Representações Acerca da Maternidade no Contexto da Depressão Pós-Parto. Rev Psicologia: Reflexão e Crítica. 2011; [citado em 2014 mar 22]; 24(2): 335-342. Disponível em: http://www.scielo.br/pdf/prc/ v24n2/15.pdf

12. Andrade PR, Ribeiro CA, Ohara CVS. Maternidade na adolescência: sonho realizado e expectativas 
quanto ao futuro. Rev Gaúcha Enferm. [internet] 2009 dez; [citado em 2014 mar 22]; 30(4): 662-668. Disponível em: http://seer.ufrgs.br/ RevistaGauchadeEnfermagem/article/viewFile/9032/7576

13. Perosa GB, Canavez IC, Silveira FCP, Padovani FHP, Peraçoli JC. Sintomas depressivos e ansiosos em mães de recém-nascidos com e sem malformações. Rev Bras Ginecol Obstet. [internet] 2009 ago; [citado em 2014 mar 22]; 31 (9):433-9. Disponível em: http://www.scielo.br/pdf/rbgo/ v31n9/a03v31n9.pdf

14. Santos Junior HPO, Silveira MFA, Gualda DMR. Depressão pós-parto: um problema latente. Rev Gaucha Enferm. [internet] 2009 set; [citado em 2014 mar 22]; 30(3): 516-24. Disponível em: http://www.seer.ufrgs.br/index.php/Revista GauchadeEnfermagem/article/view/8062/6997

15. Lopes ER, Jansen K, Quevedo LA, Vanila RG, Silva RA, Pinheiro RT. Depressão pós-parto e alterações de sono aos 12 meses em bebês nascidos na zona urbana da cidade de Pelotas/RS. J. bras. psiquiatr. [internet] 2010; [citado em 2014 mar 22]; 59(2):88-93. Disponível em: http://www. scielo.br/pdf/jbpsiq/v59n2/a02v59n2.pdf

16. Strapasson MR, Nedel MNB. Puerpério imediato: desvendando o significado da maternidade. Rev Gaúcha Enferm. [internet] 2010 set; [citado em 2014 mar 22]; 31(3): 521-8. Disponível em: http:// www.scielo.br/pdf/rgenf/v31n3/v31n3a16.pdf

17. Carmona EV, Coca KP, Vale IN, Abrão ACFV. Conflito no desempenho do papel de mãe em estudos com mães de recém-nascidos hospitalizados: revisão integrativa. Rev Esc Enferm USP. [internet] 2012 abr; [citado em 2014 mar 22]; 46(2): 505-512. Disponível em: http://www.scielo.br/pdf/reeusp/ v46n2/a32v46n2.pdf
18. Maçola L, Vale IN, Carmona EV. Avaliação da autoestima de gestantes com uso da Escala de Autoestima de Rosenberg. Rev Esc Enferm. [internet] 2010 set; [citado em 2014 mar 22]; 44(35): 570-7. Disponível em: http://www.scielo.br/pdf/ reeusp/v44n3/04.pdf

All authors participated in the phases of this publication in one or more of the following steps, in According to the recommendations of the International Committee of Medical Journal Editors (ICMJE, 2013): (a) substantial involvement in the planning or preparation of the manuscript or in the collection, analysis or interpretation of data; (b) preparation of the manuscript or conducting critical revision of intellectual content; (c) approval of the versión submitted of this manuscript. All authors declare for the appropriate purposes that the responsibilities related to all aspects of the manuscript submitted to OBJN are yours. They ensure that issues related to the accuracy or integrity of any part of the article were properly investigated and resolved. Therefore, they exempt the OBJN of any participation whatsoever in any imbroglios concerning the content under consideration. All authors declare that they have no conflict of interest of financial or personal nature concerning this manuscript which may influence the writing and/or interpretation of the findings. This statement has been digitally signed by all authors as recommended by the ICMJE, whose model is available in http://www. objnursing.uff.br/normas/DUDE_eng_13-06-2013.pdf

\footnotetext{
Received: $03 / 08 / 2013$

Revised: 03/16/2014

Approved: 03/26/2014
} 